new information on congenital heart disease, diseases of the renal tract, endocrine disorders, and neurosurgery. The chapter on diseases of the eye has been greatly enlarged, and the new chapter on psychological medicine meets a need.
These volumes, handy in size, are well produced in clear print on good quality paper. The reviewer recommends them with confidence to all engaged in paediatric nursing. Certainly every nurse-training school would benefit by having copies in the reference library.

\title{
Correspondence
}

Sirs,

\section{Fetus vs. Foetus}

Cambridge students who have attended my Embryology classes during the past decade will know (if they remember) that our American colleagues are correct (though perhaps unwittingly so) in their spelling of the word fetus. One recognizes that language is like a living organism, and undergoes evolutionary change. We would, however, be reluctant to abandon our own paediatrics, gynaecology, or orthopaedics. But there is nothing, except the always interesting 'history of errors', to recommend the traditional English and French foetus.

Classical Latin authors had a word for what a mother brought to birth: it was unquestionably fetus. The putative root is $f e$-, from feo, fere (to bear), which has given us a host of splendid words such as female, fecund, felicitude - and also, it may be noted, effete, for one who has ceased producing offspring.

Fetus was the only spelling in use up to the year 600 A.D. ${ }^{1}$ No originality is claimed for the observation that the new spelling was introduced by Isidorus (c. 560-636 A.D.), who was Archbishop of Seville, and one of the most influential figures in the Dark Ages. His literary output was prodigious. ${ }^{2}$ His learning, though considerable, was not really adequate to his purpose, and much that he wrote in, for instance, his twenty-volumed 'Etymologies' was erroneous, partly because, as has been noted, ${ }^{3}$ his Latin was 'not pure'. For all his errors though, he was one of the few who kept alive some semblance of classical learning at a time matched only by our own for general indifference and insensitivity to history. ${ }^{4}$

Isidorus appears to have been misled by the Greek

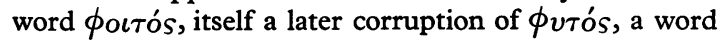

meaning 'fertile'. The Shorter Oxford Dictionary (3rd edition 1947) gives only the spelling foetus, and says that 'the better form with $e$ is almost unknown in use'. But Partridge $^{5}$ states the true facts quite bluntly, in a way that should give pause to authors and editors alike.

It would be a gesture towards Anglo-American entente if Western Europe were to abandon an error that has persisted for over 1300 years. Perhaps in return our American colleagues would leave their word pediatrics to the footmen, where it could conceivably, though still incorrectly, belong.

As to plurals, the correct form is fetūs with the long second syllable (never, of course, feti, from the sight and sound of which both mind and heart recoil). But perhaps it would be altogether too pedantic to insist on such 'difficult' plurals these days, and I for one would settle for fetuses.

$$
\begin{gathered}
\text { Yours, etc., } \\
\text { BERNARD TowERS } \\
\text { Anatomy Dept., University of Cambridge. }
\end{gathered}
$$

1 Souter, A. (1949). Glossary of Later Latin. Oxford.

2 Encyclopaedia Britannica. (1910). 11th ed. Cambridge.

3 Wace, F., and Percy, W. C. (1911). Dictionary of Christian Biography and Literature. London.

4 Towers, B. (1966). Medical scientists and the view that history is bunk. Persp. Biol. Med., 10, 44-55.

5 Partridge, E. (1958). Origins: a Short Etymological Dictionary of Modern English. London.

[The question raised by Dr. Towers has, by coincidence, been asked simultaneously by J. D. Boyd and W. J. Hamilton in Brit. med. J. (1967), 1, 425. The Editors would welcome etymological comments before deciding whether to change the conventional spelling of foetus.]

\section{Donald Paterson Prize Essay}

A prize essay competition will be held, open to medical practitioners registered in the United Kingdom for not more than ten years. The value of the prize will be twenty-five pounds.

The subject of the essay shall be related to paediatrics but will be chosen individually by candidates. The essay shall consist substantially of unpublished work.

Entry forms and further information may be obtained from the Honorary Secretary, British Paediatric Association, Institute of Child Health, 30 Guilford Street, London W.C.1. The closing date for entries will be June 30, 1967. 